\title{
Index Factors for Assessing the Scientific Journal Validity, It's Articles and Their Authors
}

\section{Izet Masic*}

Academy of Medical Sciencees of Bosnia and Herzegovina, University of Sarajevo, Sarajevo, Bosnia and Herzegovina

\begin{abstract}
The transition from the $20^{\text {th }}$ to the $21^{\text {st }}$ century was one of the most dynamic periods in the history of science and scientific journals. Numerous articles are almost entirely prepared in electronic form, so the creation of many databases with full texts become relatively easy problem to solve. A large number of the journals appeared in form of open access in electronic form available for end users - readers. But often the question raises about the value of these scientific journals with journals that are still available and already present on a commercial basis. In particular, this applies to journals within medicine, where reliability and quality, or the credibility of the information itself is of great importance for science itself.
\end{abstract}

Keywords: Medicine; Journals; Indexes of journal scientific validity; Index databases

\section{Introduction}

The journal represents one of the main communication media, particularly in the field of natural, technical and biomedical sciences [1]. The most important role of scientific journals is the publication and dissemination of scientific articles [2-5]. The source of scientific and technical information can only be human - scientist or expert whose scientific and professional work creates knowledge in an area [1,610]. The primary publication represents the document containing the text with basic informations in original form prepared by the author. Biomedical journals according to field covered can be divided into four groups: highly specialized journals (publish materials from the specific field), general biomedical journals (intended for a wide range of users), classic journals (deals with problem from only one biomedical field) and primary research journals (professional literature and a major source of scientific information) [1]. Equally important is the role of received articles evaluation carried out by reviewers of particular journal [1,3,11-15]. Review process has, in fact, a key role in evaluating the methodological validity $[11,16,17]$, interpretation and conclusions of the research results described in paragraphs [18-21]. The following role of function of a journal is protection of author's intellectual property [22-25], its presentation to the scientific community and securing the path for gaining professional recognition and advancement [22-25]. Today, scientific journals have a significant role in the implementation of science policy and decision-making in science because rating of the journal may influence decisions about financial support to scientific projects, the ranking of academic and scientific institutions and the advancement of individuals in the scientific and academic system. As the number of scientific journals in the world increases daily, the scientists were able to follow everything that is published in the field of their interest and they are forced to select literature which will allocate professionals precious time and read it for their needs. For this reason, librarians, scientists and publishers are interested in assessing the quality of the journal in order to subscribe to the most relevant scientific journals for their customers and follow what is published and publish their articles in them.

Zwemer, lists seven criteria for assessing the quality of the journal [1-3]:

- High standards for manuscript acceptance;

- Representative Editorial Board with appropriate representation of individual disciplines;
- Critical process of reviews;

- Regular publishing;

- Indexed in major databases;

- High degree of confidence in the content by readers;

- High frequency of citations in other journals.

\section{Criteria for evaluation of scientific work in research}

Evaluation of a scientific article refers to the finding quantitative indicators (index) of the scientific research success. The science that deals with this is called scientometrics.

So far has not been found a completely satisfactory evaluation criterion of scientific work and scientists because each offered criterion has more or less its flaws, however, it is considered that more criteria's is used the evaluation is more objective.

There are two types of evaluation criteria for certain scientific works $[1,3]$ :

- Qualitative: Reviews i.e., expert opinion - is considered the most reliable, but also the least objective criterion.

- Quantitative: Scientometrics indicators - considered the most objective criterion but also the least reliable.

Review-expert opinion (peer review) is an independent criterion because a reviewer is not associated with specific scientific work not with the authors. It is considered to be a competent criterion because a large development of science reduces the number of competent experts for certain specific research areas.

Scientometrics is part of Scientology (the science of science) that

*Corresponding author: Izet Masic, Academy of Medical Sciencees of Bosnia and Herzegovina, University of Sarajevo, Sarajevo, Bosnia and Herzegovina, Tel: 387-33226-896; E-mail: imasic@lol.ba

Received February 29, 2016; Accepted March 02, 2016; Published March 15 2016

Citation: Masic I (2016) Index Factors for Assessing the Scientific Journal Validity, It's Articles and Their Authors. J Forensic Anthropol 1: 103.

Copyright: (C 2016 Masic I. This is an open-access article distributed under the terms of the Creative Commons Attribution License, which permits unrestricted use, distribution, and reproduction in any medium, provided the original author and source are credited. 
analyzes scientific papers and their citations in a selected sample of scientific journals.

\section{Indices for measuring the validity of scientific research}

There are four indexes by which it is possible to measure the validity of scientific research [1,3,22-25]:

1) Number of articles;

2) Impact factor of the journal;

3) The number and order of authors;

4) Citations number.

The number of articles speaks more about productivity than about quality. It includes: scientific and professional articles published in extenso in journals, books, monographs, articles published in extenso in indexed journals.

Impact factor is the result of statistical operations which establish expected citation of a publication based on the two-year assessment. This is actually the value of the journal, not the particular publication or author. However, there is no doubt that many prestigious journals with high impact factor publish articles of a high scientific level. It is closely related with the high impact factor of the journal. It depends on $[1,14-16]$ :

- Journal quality;

- The language in which it is published;

- $\quad$ Area covered;

- Journal distribution.

Impact factor represents simple quantification of the data for scientific production, but we have to relate it with the area of research [1]. There are significant differences, for example, a top journal in laboratory medicine is Clinical Chemistry (IF $=5.454$ ), in nephrology is the Journal of the American Society of Nephrology (IF = 7.371), in oncology a top journal is CA A Cancer Journal for Clinicians (IF = 63.342), a total of seven journal has impact factor over 10. Cell (IF = 29) and Nature Review Molecular Cell Biology (IF = 31) are top journals in basic cell science, while 16 other journal has a higher impact factor than 10. Assessing impact factor should be done on the basis of "weighted impact factor" in the specific research field.

Factors of the journal influence make one of the important parameters for research funding. Editors have great power to choose highly qualified reviewers for selection of the articles. They indirectly affect the financing of future research of various scientists and institutions.

\section{Number of citations}

The citation is influenced as below $[1,3]$ :

- $\quad$ The quality of the article;

- Understanding of the article;

- The language in which the article is written;

- Loyalty to a certain group of researchers;

- Types of the articles;

- $\quad$ Benefits in terms of "I'm quoting you, and you quote me"
- "benefit" in the sense of "I will not quote it because he/she is my competitor" and so on.

Measures of scientific echoes are more increasingly used for academic promotion and evaluation. They are also used for the assessment of departments at universities and research centers. Traditionally was used journal impact factor.

As an indicator for evaluation of scientific publications in the world is used the representation of articles in citation databases, an indicator of the potential value and impact of some article measured by the number of citations, or the status of the journal with regard to its impact factor (IF). These indicators can be obtained exclusively based on data and content of ISI citation databases. By extending Genetics Citation Index, as multidisciplinary database for natural applied Sciences is created the Science Citation Index (SCI) in 1963 which included a literature from 1961. The initial corpus of journals in SCI was 600, today it already covers over 5,900 journals.

Evaluation of scientific activity is usually measured by the scientific productivity and its echo measured by citation analysis. Citation analysis measured the types of citations, number of citations, selfcitations, for example, the author/co-author, institution, journal, country, or independent citations. With regard to the evaluation of the status of the scientists, institution or country, it does matter in which journals are published the results of a specific research and the extent to which they are notices, who spotted them and registered as citations. Therefore, very often as an indicator in evaluating scientific work of individual scientists or institutions is also used the status of the journal itself, given its impact factor (IF) in which the article was published, as well as the status of the journal that particular article cited.

Neither of these two databases does not take into account the monographs, which are the main source of information, as well as textbooks or student's scripts.

National journals are important for the national scientific community. They should primarily serve for training, with brief information to the scientific community. Of course, they should also publish original articles. Publisher and scientific society should strive for its inclusion in the international databases, especially Scopus and Web of Science.

There are also new scientometric techniques for evaluation of journals and scientists - citations density, half-quotations, Erdoss number (mostly used by mathematicians) or h index [23]. All these new instruments use sophisticated statistical and mathematical processes. Hirsch index (h-index) is defined as the ratio of the number of papers and the number of citations that is equal to or higher than the number of papers. This index should be used for the assessment of persons who join the university staff or prestigious associations. The value of $h$ index of 10-12 is for prestigious universities a sign for a permanent job without re-election. For membership in the American Physical Society required index is of 15-20, and for membership in the US National Academy of Science over 45 [1].

\section{Number of authors and their order in the published article -} number of authors and their order

It is calculated in a manner that one author has a contribution - when it comes to the article written by multiple authors then the contribution of each author is calculated as $1 / \mathrm{n}$ and is for example in the case of the article by two authors contribution of the first is 0.7 and another 0.3 or in the case of multiple authors contribution of the 
first author is 0.6 , the second 0.3 , the third 0.2 and the others 0.1 . The contribution of the first author is 100 , and each subsequent the half the size of the previous one.

\section{Indices for Measuring the Scientific Value of the Journal, Articles in Journals and Author's Articles}

\section{H-index}

Physicist Hirsch [11] aware of the shortcomings of previous evaluation indicators of scientific productivity, the number of published papers and echo measured by the total number of citations, the average number of citations per paper, the number of articles by the above average number of citations, the potential value of papers published in journals with a particular IF, introduced indicator that can measure a wider echo and recognizable influence of individual scientists or journal. He suggested that only one number the "h-index" as a simple and useful way to characterize scientific activity of researchers. A scientist has a certain h-index if any of its $\mathrm{Np}$ articles received at least $h$ citations, while the other $(N p-h)$ papers have $\leq h$ citations. In practice this means that if the author has an h-index of 10 , then it published 10 or more articles, while its 10 articles received at least 10 citations, while his other articles are quoted less than ten times. The total number of citations in this case may be at least 100 .

$\mathrm{H}$-index as a scientometric indicator, in the basis is used for comparison of scientists in the same area and approximately of the same experience and the same argument applies to journals. The two scientists with similar h-indices are comparable in terms of their overall scientific productivity and echoes, even if their total number of papers and citations is very different. That is, comparing the two scientists (with approximately same experience) with a similar number of publications and/or similar total number of citations, but different $\mathrm{h}$-indices, argues in favor of greater "visibility" of scientists with a high h-index [12].

According to the opinion of Brown and associates the h-index combines in the specific and balanced way effects of the "quantity" (number of publications) and "quality" (number of citations).

Masic et al. [23] find that h-index has several advantages. It combines productivity with echo, is not sensitive to extreme values in terms of articles without citation or to articles with above-average number of citations and directly enables the identification of the most relevant articles with regard to the number of citations received. Not rare is situation that a scientist publishes several important articles and that these articles have extremely a lot of quotes, but the h-index is not particularly high.

It is often case that the scientists with a high h-index working as a team and publish articles with a large number of authors (more than 50) and mutually quote each other, as is the case for example, in the field of high-energy physics. Batista and van Raan, warned that in case of h-index it is important to explore the impact of the number of authors in the total number of citations. These authors have shown that as the greater the number of authors is, the greater is the number of self-citations, which can directly increase the h-index, if they do not exclude self-citations. On the other hand, it is important to keep in mind that for a narrow scientific fields, for example, which is still in development, self-citation is logical and expected phenomenon.

When all of the above is taken into account, h-index basically defines recognition, or the consistency of individual scientist or journal, in particular field. In this case the recognition means that the scientist has a larger number of papers, all of which received a relatively large number of citations and so called independent citations. Independent citations are citations that the author receives from his unknown colleagues outside its institutions, and in the case of small country, outside their country.

As for other indicators for validation of scientific work, also for the h-index in the interpretation of the values is important to take care not only about discipline or area, but also branches, as well as the actuality of the work the scientist deals with. Hirsch on the basis of its calculation, it is proposed as a guide for the evaluation of physicists the world's leading research universities for the advancement associate professor $h-12$, full professor $h-18$, and membership in the National Academy of Science of the United States of America the average $\mathrm{h}-45$, except for some cases. It is proposed that as an indicator for successful scientist's physicists, with 20 years of research, h-index is 20 , while the h-index of 40 indicates "outstanding scientists in the highly successful laboratory". Author also report citation examples of physicists Nobel Prize winners, whose h-index values range from 70 to 90 . The average h-index physicist candidate for the Nobel Prize in the twenty-year period from 1985 to 2005 was 35 .

According to Hirsch, the most cited 10 scientists in the field of natural sciences, from 1983 to 2002, had a median h-index of 57, which is much higher than for physicists. But, natural sciences are too broad an area to be easily compared to the index of molecular biologists and biologist who specializes in ecology, or biodiversity or floristry or zoology.

Cronin and Meho, conducted a study comparing the h-index and the total number of citations in the field of Information Science. They analyzed 31 scientists with the most citations from the Faculty of Information Science in the USA, in the period from 1999 to 2005 according to SSCI most cited IS scholars. The range of their h-index values was from 5 to 20 , with the fact that they excluded self-citations. They proved that there is a positive correlation between the h-index and the number of citations, which suggests that the total number of citations is indeed reliable indicator of echo and impact of the articles of the scientists. The mean h-index for information sciences was 11 Oppenheim analyzed British scientists in the field of library and information sciences and got the mean h-index of 7 .

The scientific community has shown great interest in the h-index as a scientometric indicator, so that Scopus and WoS databases, with the number of articles, number of citations, the average number of citations offer automatic calculation of the h-index, including all kinds of quotes.

Except for authors, h-index began to be increasingly used as an indicator for evaluating journals. Masic et al. [3] have made a comparison of certain journals according to IF and h-index. The results showed that the journals Physical Review Letters, Astrophysical Journal and the Journal of the American Chemical Society are in the top 20 by the h-index, while according to the IF, these three journals were not among the top 100 journals, which shows an incomplete correlation of these two indicators. Based on all of the facts, h-index is certainly one of the indicators that contribute to the overall assessment of the scientific work of individual scientists, institutions, field, journals and so on. It would be nice to observe it separately, or regardless of the subject area, length of scientist's professional engagement, science productivity, co-authors, the total number of citations and the type of citations and other relevant parameters $[1,3,24]$. Three bibliometric databases for analysis and evaluation of quotations through $h$ index: Web of Science 
(Thomson Reuters), Scopus (Elsevier) and Google Scholar. Although Google Scholar and Scopus seems to provide a greater number of citations $[1,3,24,25]$, there are mixed information about $\mathrm{h}$ index. De Groote and Raszewski [1,3] reviewed 31 member faculties located in US Midwest, and concluded that more than one database should be used to calculate the $\mathrm{h}$ index. They further recommend that, as since the scales of $\mathrm{h}$ index differ between databases, comparisons between researchers should be done in a particular database $[1,3]$.

\section{Impact factor - impact factor of the journal}

What is the Impact Factor?: Impact factor (Impact factor) is one of the quantitative criteria applied in the ranking, categorization, evaluation and comparison of scientific journals. It is "an objective tool that allows critical appraisal of leading international journals on the basis of quantitative, statistical information derived from data on citations [14]".

Echo factor measures the frequency with which on average an article published in a journal is quoted within a certain period of time. This indicator, therefore, does not measure the distribution of citations themselves that certain article published in a journal receive, but just their average frequency. One of the longest and best-known indicators of scientific merit of a journal is undoubtedly the Impact Factor. It is a number that shows how many times in average is quoted one scientific article in a journal in a given period. Every year is calculated impact factor for all journals that refer to several major databases (Science Citation Index Expanded and Social Science Citation Index) and for all journals that were quoted in them. The impact factors of journals are now widespread criterion for selection of journals in many libraries, as well as for the selection for authors in which journal they will publish the articles.

The values of impact factor for individual journals are published annually in the statistical database by Thomson Reuters Journal Citation Reports (JCR). This database, which was created in 1975 by Eugen Garfield, can be accessed directly or through WoS platform. Journal Citation Reports is a quantitative tool for ranking, evaluating, categorizing and comparing journals. Besides the impact factors, indicators of scientific value of the journal are: 5-Year Impact Factor, Immediacy Index, Cited and Citing Half-life. Journal impact factor is calculated by dividing the number of citations obtained in the current year to papers published in the last two years the number of papers published in the same time period. Impact factor of 1.0 means that, on average, paper in the last two years have been cited once. It is interesting to analyze the impact of self-citations of the journal on its impact factor. Excessive self-citation in journal leads to an increase in impact factor and unrealistic ranking of journals within the subject area. This year, 38 journals is suspended by Journal Citation Reports lists of impact factors due to excessive self-citation or because of their strong citation of papers published in a certain journal in the articles published in the other, always in the same journal, by the principle of citation stacking. The frequency of self-citation ranged between $59-90 \%$. These journals will, in the forthcoming period, be followed and checked in order to satisfy all the criteria and standards required for inclusion in the WoS database. Since 2007 Journal Citation Reports also are presented by Eigen factor Score and Article Influence Score. Such information can be reached directly via the Eigen factor website (http:/www.eigenfactor. org). The calculation of these indicators based on citation data Journal Citation Reports, meaning that they apply only to the articles and journals that are indexed in the WoS. Eigen factor Score measures the number of citations that papers published in a journal in the past five years received in the current Journal Citation Reports year, taking into account the data from which journal they are published. Journals that have cited more and more impact on the network citations than journals that are less quoted. Additionally, Eigen factor Score devoid the self-citation influence of journals, because it excludes the references cited papers published in the same journal. Article Influence Score is determined by the impact of papers published in a journal in the first five years of publication. Its mean value is 1.0. Value greater than 1.0 means that all papers published in the journal have an above-average impact, while less than 1.0 indicates work with below-average influence.

How is the Impact Factor calculated?: Quotes, as part of the scientific journal are a useful tool for authors since they provided argument citing of previously published article without having to describe it in details. Quotes allow readers to find relevant prior information on the given topic.

Given the steady increase in the number of scientific articles, the number of co-authors and the references for the article, it is not surprising that the number of citations is growing even faster than the number of scientific articles. Quotes are often used as a measure of importance/impact that the article had given in the scientific community. Citing and the self-citation of articles can be used increasing IF but should be careful when it comes to this way of evaluating the quality of a particular article. Garfield [14] first mentioned the idea of using the IF. Its main objective was to find an indicator to select scientific journal that will be included in the database called Science Citation Index (SCI). Also, by using the quote in an article published in the journal, Raising proposed measure quality/importance of a journal which he called „Index of the Research Potential Realized. In 1960, Garfield standardized IF and applies it to all the relevant journals for SCI. Winkler gave a comprehensive description of the IF in his review of the publication of scientific journals in 2000 and the impact factor of 2004. Over time, in parallel with data on the variability of the original IF, there have been many attempts to change the IF, but the original concept is still in use. Thus, the impact factor of scientific journal is the ratio between the number of citations received by articles published in the journal in a given time period. IF is published in the Journal Citation Report journal (Thomson Reuters, New York, USA) is calculated by dividing the number of citations received by the journal in a given year with the number of cited articles published in the same journal in the two previous years. So impact factor value is obtained by dividing the number of citations for the last two years with a number of publications in the same two years.

This agrees with the original Garfield - this term. The formula for calculating the IF looks like this:

$$
\text { IF (e.g. for 2015) }=\mathrm{C} / \mathrm{P}
$$

C is the number of citations in 2015 ,

$\mathrm{P}$ is the number of citations of articles published in the same journal during 2013 and 2014

The explanation is necessary for the concept of "citable texts". It is widely known that scientific journals can contain texts (e.g. letters, obituaries, summaries of conferences) that are rarely mentioned. This choice of text that can be specified only one among the controversies associated with IF. As we continue, we will be witnesses of numerous controversies. Thus, even in these early stages of the text, caution should be exercised when using the given numerical value of IF for evaluation purposes. It may happen that a journal with a large number of citations in a given year does not have a high IF, as the number of citations of articles published in the two previous year's counts. 
It should also be clarified that the high IF journal does not mean that every article in it has a high rate of citations. IF applies to a journal, not for individual articles. In fact, it is quite possible that in a journal with high IF some of the published articles were not cited at all. Several studies in this case, testified about the discrepancy between the IF of the journal and citations of individual articles published in it. More broadly, we must understand that the article published with a high IF can have more chances to be read, but published in a journal with a low IF. In other words, IF of journal may carry some weight in the citations of articles published in the journal. So far, we have concluded that the IF determines quotes individual articles, not vice versa.

When comes to the citations, including the calculation of IF, we need to be aware that it can be self-citations among them. They are defined as read an article in a certain journal that quoted in the previous article of the same journal. Garfield, calculated that self-citation amount to about $13 \%$ of the total number of citations. A large number of self-citations can be found in journals for small and relatively isolated branch of science. On the other hand, multidisciplinary journals have a lower proportion of self-citations. Groups of scientists can significantly add to the IF of the journal with their own quotes. Thus, the more rigorous study of IF, should calculate the correct IF omitting self-quotations.

Since the publication and citation can vary over the years, we can try to correct the calculation of IF for more than two years prior. IF for 5 or 10 years is definitely more trustworthy than the standard (two years). The difference between a standard IF and one for 5-10 years is particularly important when the comparisons is made between different areas of science, since there are some specific citation patterns in different fields of science. For this discussion is particularly relevant research of Glaenzel and Schoepfin dealing with the aging of the published data, using quotes that are received. Based on their results, the authors propose to take three years to calculate the IF, as a useful compromise between the fields of science with relatively rapid aging (e.g. The natural sciences and experimental physics), as opposed to those with a longer duration (e.g. Some parts physics and social sciences). Garfield is accepted that a long period of time may be more relevant for the calculation of the IF in the field such as clinical medicine (Clinical Medicine).

Journal Citation Report classifies science into about 200 categories. The extended number of years can be a practical solution, but the fact remains that some scientific journals are difficult to classify in any category (e.g. interdisciplinary) so many could easily be divided into several.

Example: The journal American Economic Review in all articles from referred journals in WoS published in 2006 was cited 5,913 times. Of that number, 584 times cited papers are published in 2005 and 2186 times those papers were published in 2004. The journal in 2005 the published 148 papers, and in $2004-193$ articles. Then its influence factor calculated as follows: $(584+2186) /(148+193)=8.12$ So, impact factor of the journal American Economic Review for 2006 is 8.12. This is calculated by factors of influence eliminate differences that might arise as a result of greater periodicity (more issues per year) or duration of the journal publishing.

How the Impact Factor is published?: Impact factor is published in the Journal Citation Report in June of each year for the previous one. The mere calculation is performed on the basis of the situation in all three citation databases (SCIexpanded, SSCI, AHCI) on the first day of March. The journal, in most cases, obtained impact factor after two years of reporting in WoS. This means that if the journal started to be published for example in 2008, it will receive the Impact Factor for 2010, which will be published in June of 2011.

Science Citation Index (SCI) is closely associated with the impact factor. Today it is based on the Web of Science, which organizes and produces E. Garfield. The first volume of the Science Citation Index was published in 1961. This parameter shows the number of citations to a particular article in selected database from the journal. This database contains approximately 8,000 journals. The monopoly of the database completed in 2004 and today it is a real alternative to Scopus, which includes over 14,000 journals. Scopus database is organized by Elsevier and more focused on the European region. Neither of these two databases does not consider itself monographs, which are the main source of information, as well as textbooks and student scripts.

- Science Citation Index (SCI): SCI Expanded is the bibliographic and citation database in the field of natural and applied sciences. Handles content from around 5900 of the world's leading scientific and technical journals. In this manner covers about 150 scientific disciplines.

- Citation indices and JCR database (Journal Citation Reports): Based on data from citation databases SCI and SSCI (Social Science Citation Index), Garfield [14] created special statistical database Journal Citation Reports. Journal Citation Reports is a quantitative tool for ranking, evaluating, categorizing and comparing journals [4]. Journal Citation Reports Science Edition, handles around 5700 journals in approximately 150 disciplines. However, the use of impact factors, and especially the so-called. standard or Garfield impact factor, as one of the main indicators in the evaluation of one's work, leads to the conclusion that this is a misunderstanding of its true meaning. Impact factor of a particular journal is a measure of the frequency with which the "average article" in a journal cited a specific time Period.

\section{Review of Most Important Biomedical Databases}

The database is an organized set of data. It consists of identically defined and described records. Every scientific article is a record of the data written by the rules recommended by several scientific associations and committees [1]. Databases containing information about the author (including bibliographic data and abstracts) and original article. Set of data is determined by the database type. Databases are processing the best professional journals and publications. Reliability and quality of information is guaranteed by the editors of the database. The most important databases are located in the famous university/academic centers. For all databases apply the same basic information: author (name): Address: journal in which is issued; year of publication [1]. Databases can be divided into three categories $[1,2]$ :

\section{Bibliographic databases}

Content of bibliographic databases related to articles published in various journals and publications. They contain information such as author, title, source, abstract, year of publication, the institution from which comes the author, type of publication, original language of bibliographic database. Bibliographic databases may vary in comparison to the area and structure of bibliographic records that enable description of a very detailed and unique shape. These databases are linked with other databases and the original version of published articles [1].

\section{Citations databases}

Citation databases are also bibliographic databases. What differs them from bibliographic databases is in the articles, processed and used 
references, quotes by the author at the end of article. They serve us to learn how the articles are cited and used to assess the quality of the cited article and assessment impact of individual article to a specific number of citations [1].

\section{Databases with full texts}

They are largely a collection of journals in electronic form of one or more publishers. They contain bibliographic information (as well as bibliographic database) and various other data. It should be point out the differences between databases with full text and bibliographic databases containing only link to the full text. Databases with full texts usually offered article in HTML and/or PDF format [1].

\section{Relevant citation databases}

Bibliometric indicators of scientific journals usually are formed according to the data from the two most famous current bibliographic and citation databases -Web of Science Core Collection (WoSCC) and Scopus [1,4]. Although freely available, database of Internet search engine Google Scholar (Google Scholar) has not been generally accepted in the scientific community to judge scientific activities. Based on data from WoSCC (Web of Science Core Collection, 2014) is calculated the best known bibliometric indicator of journals, the socalled Impact Factor, which Thomson Reuters publishes in its other product - database Journal Citation Reports.

Thomson Reuters Corporation is a provider of business information created in April 2008 with two parent companies, Thomson Reuters Corporation and Thomson Reuters PLC. Thomson Reuters Web of Knowledge SM is a research platform that provides access to content that is objective and powerful tools for retrieval of social, art and humanity sciences. This intelligent research platform provides access to the world's leading citation database. Quotes symbolize a collection of scientific ideas. Web of Knowledge has single index that lists and calls upon article that allows the user to see an explicit link between current research and previous research papers. The database includes the following: 23,000 academic and scientific journals, 23 million patents, 110.00 proceedings, 9,000 web pages, coverage since 1900 year to date, more than 40 million sources, the possibility of simultaneous use of multiple databases. Some of the most important medical databases are: "The National Library of Medicine (NLM)"', in Bethesda, Maryland, which is part of the "National Institutes of Health, US Department of Health and Human Services (HHS)"'; MEDLINE (US National Library of Medicine's) which contains over 19 million references related mostly to biomedical science; PubMed Central (US National Institutes of Health's National Library of Medicine (NIH/NLM), then others such as Embase, Scopus, Scirus, GFMER, DIMDI, Cab Abstracts, Vinita, ScopeMed, Google Scholar, Index Copernicus, and many other databases.

Based on data from the Scopus citation is calculated by two recent bibliometric indicators - SCImago Journal Rank (SJR), which is available for free on the portal SCImago Journal and Country Rank in 2014 and Source Normalized Impact per Paper (SNIP), which is published on pages CWTS Journal Indicators. Both indicators are available as part of Scopus, in the part in which the plates will be enabled to browse the journal (Browse Sources). When talking about the citation databases, should always bear in mind that they are constantly and daily developing and changing. It changes their policy development, including some new journals, enhance the search capabilities and the like, and therefore it should be noted that the published analysis always refers only to the time in which this specific study conducted.
Web of Science Core Collection (SCC): Most bibliometric research is based on data from Thomson Reuters database citation index Web of Science Core Collection (Figure 1) [4], and in particular to those of the three most famous, which indexed scientific journals: from the Science Citation Index Expanded (SCI-EXP), Social Science Citation Index (SSCI) and Art and Humanities Citation Index (AHCI). Collection citation index WoSCC available to users since the beginning of 2014 through the new platform Web of Science. The collection consists of: Science Citation Index Expanded (SCI-EXP) which covers an area of natural, technical and biotechnical sciences and biomedicine and health, and includes an 8628 journals $[1,4]$ :

- $\quad$ SCI-EXP indexed journals since 1900, and data on their citations recorded since 1955. SCI-EXP actually expanded the Science Citation Index (SCI), which it is no longer separately searchable and indexed much smaller journal (total 3757).

- Social Science Citation Index (SSCI), which covers the area of Social Sciences, a total of 3125 indexed journals. SSCI indexed journals since 1900, and data on their citations recorded since 1955.

- $\quad$ Arts and Humanities Citation Index (AHCI), which covers an area of humanities and arts area, a total of 1,729 indexed journals. A and HCI indexed journals since 1975, and since that year and recorded information about their citations.

- Book Citation Index -science (BKCI-S), which indexes the books in the field of natural, technical and biotechnical sciences, as well as in the field of biomedicine and health in the period from 2005 to the present.

- Book Citation Index - Social Sciences and Humanities (SSH BKCI) that from 2005 onwards indexed books in the field of humanities and the arts area.

- $\quad$ Conference Proceedings Citation Index -science (CPCI-S), which indexes of conferences in the field of natural, technical and biotechnical sciences and in the field of biomedicine and health from 1990 onwards.

- Conference Proceedings Citation Index -Social Science and Humanities (CPCI SSH) which indexes of conferences in the field of humanities and artistic areas from 1990 onwards. Both editions CPCI-a (CPCI-S or CPCI-SSH) currently indexed more than 110,000 conference proceedings.

- Current Chemical Reactions (CCR-EXPANDED), chemical index that adopts the latest synthetic methods have been published in more than a hundred world's leading journal in the field of organic

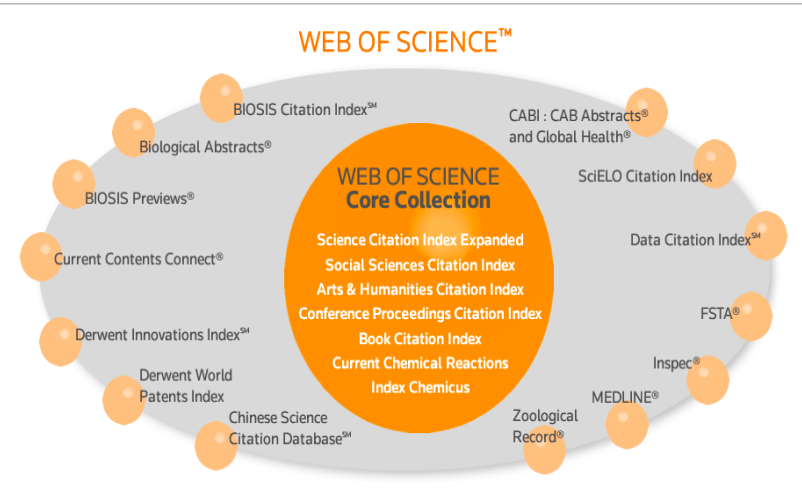

Figure 1: Web of Science Core Collection [3]. 
chemistry. It covers the period from 1985 to the present day, and includes structured data of the National Institute of Industrial Property (Institut National de la propria Industrielle), which date back to 1840.

- Index Chemicus, chemical index which covers more than one hundred world's leading journals in the field of organic chemistry from 1993 to date and provides access to information about chemical compounds. Index Chemicus text is structured and searchable, and offers comprehensive graphical summaries, important diagrams reaction and complete bibliographic information [1].

Preconditions for inclusion in the journal mentioned citation indexes are mainly related to:

- Criteria related to the standards of the very publication that includes regular publishing of a journal, respect international editorial conventions (informative journal title, the shortened title of the article in the header, specifying the full address of each author, listing all the bibliographic data when quoting), publishing complete articles or at least, bibliographic data and summaries in English and review process.

- Thematic orientation of the journal - whether a journal theme that handles enrich the Thomson Reuters database or this area already covered by other participating journals.

- The international orientation of the journal - whether the composition of the editorial board and author corpus of international character and are mostly nationally oriented.

- Citation analysis of journals - valuation of the journal based on citations analysis already published articles [3,23] (Figure 1).

\section{Research gate}

Research Gate is a social networking of sites for scientists and researchers for sharing documents, asking and answering questions, and finding collaborators [4]. It is the largest network of scientists, research experts and other persons [5].

ResearchGate was founded in 2008 [6] by virologists and informatics specialist Iyad Madisch. It started article in Boston, and shortly thereafter he moved to Berlin, Germany [7]. In 2009, the company began a partnership with Seeding Labs to deliver the third world surplus laboratory equipment from the United States.

According to The New York Times website was started with several options, and then began to develop over time, and facilitate the development of the foundations for the access of scientists [4]. From 2009 to 2011, the number of active users has increased from 25,000 in more than 1 million. In 2013 he completed a series $C$ financing with $\$ 35 \mathrm{~m}$ by investors, including Bill Gates. The company numbers 12 employees in 2011, but this number is increasing to 120 in 2014 [4,7].

The New York Times described the sides as a mashup of Facebook, Twitter and LinkedIn [4]. One can "follow" a research interest of some scholars, following the individual user [10]. This is a blog feature for users to write short reviews on peer-reviewed articles. ResearchGate self-index - published information about user profiles and propose members to connect with those who have similar interests [4]. When a user asks a question, it gives a sign that the scientist identified user in his user profile has a particular expertise in certain areas [6]. also has a private chat- room where scientists can share data, edit documents in common, or discuss confidential issues [9].

Research Gate is the largest customer-base in Europe and in North America [7]. Most Research Gate user is involved in medicine or biology, but also has participants from engineering, computer science and agricultural science, psychology and other fields. Research Gate statistics are mostly played on traditional academic foundation through citation indexes. Research Gate does not require review or fees. Since the accession documents usually requires a user account, Research Gate does not consider open access. Since 2009, according to BusinessWeek, ResearchGate has been influential in promoting innovation in developing countries, connecting scientists from those countries with their peers in developed countries [8]. Web site has become popular largely because of its "navigation" and "simplicity use ". Published in The International Information and Library Review conducted a study with 160 patients and found that those who use social networking for academic purposes, ResearchGate has been the most popular at the University of Delhi, but also a handful of respondents said they use SNSS [social sites netarticle] can be a waste of time. ResearchGate has been criticized for sending unsolicited calls for the co-authors of its users. These messages are written as if they were personally sent by the user, but they are sent automatically, unless the user checks the option, which encouraged some researchers to boycott services because of these marketing tactics.

\section{Academia.edu}

Academia.edu is a platform for academics to share their research papers or Academia.edu is a website for social netarticleing academics, whose mission is to accelerate research in the world. Academics use Academia.edu to share their research, as well as to monitor the deep analysis about the impact of their research, and supporting research in a particular area.

It was launched in September 2008. By January 2016 has registered about 32.5 million academics, who added about 8 million articles. Academia.edu attracts over 36 million unique visitors per month. TechCrunch noted that Academia.edu gives academics "powerful, efficient way to distribute their research" and that "will enable researcher's constant insight on how people read their texts with specialized analytical tools," and "and articles very well in Google search results ". Academia.edu appearance reflects a combination of norms of social netarticleing and academic standards. Academia.edu is not a university or institution of higher education and also the current standards would not qualify for the ".edu" top-level domain. However, the domain name "Academia.edu" is registrovano 1999. year, before the regulations require that the names .edu domain solely of accredited posts - secondary institutions. All names .edu domain registered before 2001 are inherited, even if they contain no accredited posts - secondary institutions [10]. Academic Social Academia.edu and ResearchGate, and website Mendeley, BibSonomy and CiteULike, give scientists the opportunity to publish their research and connect with each other. With millions of users, this requirement presents a significant addition to scientific communication and academic information. Therefore, there is a need to understand the role played by the changes taking place, if any, to be able to give a more dynamic development of an academic career (Figure 2).

\section{Bibliometrics, Informetrics, Webometrics}

Bibliometric methods are used for quantitative analysis of written materials. Bachelor is closely associated with one broader term "informetrics" [1,11-15] and short-term "scientometrics" [3,13,36]. Close analogy has "webometrics", which examines different aspects of the web. This type of analysis is based on the identification of the corpus of literature, i.e., publications in the broadest sense, in a particular scientific field. Analyses include different categories of 
ACADEMIA
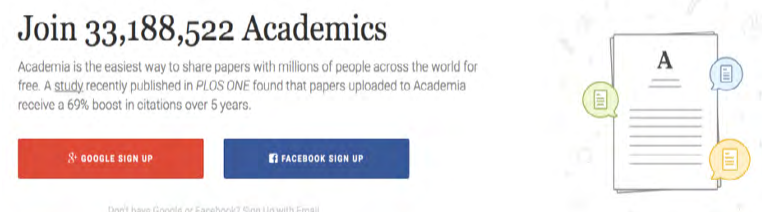

Figure 2: Academia.edu web presentation

material, ranging from articles in journals, books, papers and patents in the category of "gray literature".

\section{Webometrics}

Webometrics is relating to the quantitative analysis of the production of science, application, structure and technology in the cyber environment. Impact Analysis, Web collaboration and recognition of basic web page is considered to be the most practical advantages webometrics $[1,3]$.

\section{Informetrics}

Otto Badge introduced in 1979 a new geometric concept informetrics (it. Informetrie), which seeks to cover part of information science directed toward measuring the phenomenon of information, application of mathematical methods in solving the problem of discipline, Bibliometric and partly theory of information retrieval (Eng. Information retrieval) [1]. Informetrics according Diodatovu dictionary [1] used sometimes as a synonym for Bibliometric. But part of the author is inclined to understanding informetrics as a discipline which covers a much broader area than the bibliometrics. Nacke and others point out that informetrics and scientometrics two sister areas within information science. Since 1984, as part of the Federation Internationale de la Documentation (FID) begins to act informetrics Committee, and the first president elected administration $\mathrm{O}$. badges. The Committee has from the very beginning accepted informetrics as a generic term for Bibliometric and scientometrics. This approach gets extra force after Bertram C. Brooks as part of the First International Conference on bibliometrics and theoretical aspects of information retrieval proposed inclusion of bibliometrics and Scientometric under the umbrella of "informetrics". It was emphasized that scientometrics seeking a foothold in research relating to science policy, and bibliometrics should be more geared towards research librarian. Part of the credit for popularizing and increase the number of informetrics research belongs Eggheu L. and R. Rousseau. Their book Introduction to informetrics: quantitative methods and library, documentation, and information science published in 1990 publishing house Elsevier. In the opinion of that two authors, informetrics deals with measuring, mathematical theory, modeling of all aspects of information and storage, and retrieval of information so that "lends tools (techniques, models, homogeneity) of mathematics, physics, computer science and other [-] metry. Informetrics, according to the mentioned author duo, applied in the management of libraries, the sociology of science and knowledge, history, science, science policy and information retrieval.

\section{Scientometrics}

Scientometrics is part of Scientology science (the science of science) that analyzes scientific papers and their citations in the scientific journal selected sample $[1,3,16,19,20]$. Scientometrics is the science of measurement and analysis of science using qualitative, quantitative and computational approaches. Scientometrics with its various indexes is a reliable method for assessing the scientific development. Name of bibliometrics was introduced in the seventies and indicates a quantitative study of the process of communication by means of books and other media of communication. Scientometrics comes from the Russian language, more specifically, in 1969 the name scientometrics was introduced in the scientific field and the idea was that it studies the processes of information, the application of quantitative methods. Later Tibor Braun officially introduced name scientometrics and base journal Scientometrics [12]. The term scientometrics attributed to the book by the Russian "Naukometrija" [3,13,16] published in 1969 [1]. Vassily Vassilievich Nalimov, Russian mathematician, his first article, which can be interpreted as a scientometric 10 published in 1959 [1] and is considered the author of the distinctive contribution of information sciences [1]. What is the definition of scientometrics concerned, Nalimov and Mulchenko, authors of "Naukometrije", defined scientometric studies such as those observed science as an information process application of quantitative (statistical) method. Modern scientometrics mainly based on the article of Derek J. de Solla Price and Eugene Garfield (Garfield has founded ISI - Institute for Scientific Information which is considered the father scientometrics and methods of evaluation of scientific publications.). As a beginner scientometrics often mentioned Derek John de Solla Price and his book is well-known beyond the borders of Information Science Little Science, Big Science $[1,13,16]$ in which Price argues: "Science is a measurable substance, consequently, the manpower engaged and science, the scientific literature, talent and expenses afforded to science can be measured by properly selected statistical methods". An editorial in an editorial in the first issue of the journal Scientometrics de Solla Price summarizes, "we would be bad scientists when we could use our professional analytical tools to their own activities [1]".

Core scientometrics, therefore, stems from observations of science as a measurable substance or observing the actors and the inputs and outputs of scientific processes. The importance of de Solle Price, for scientometrics it is almost pointless to argue. After his death in 1983 the journal Scientometrics begins to sponsor the prize and a medal named after him [1]. Since 1993, the prize is awarded every two years. As of 2013-a year awarded 17 prizes. The scientometrics development is related to the development of data sources used. Given that bibliometrics central access to scientometrics, it is clear that the rich resources of bibliographic metadata are critical. In addition, an important topic in scientometrics is tracking reverb, which are publications i.e., Bonded actors had. In the scientific literature this echo, and the aforementioned relations of trust and validation, formally present the quotes that are important feature of scientific texts. In scientometrics, therefore, in addition to standard bibliographic records of scientific publications require formal written information about the net article of citations between these publications. Database with bibliographic information that includes information about quotations called citation index as among the central concepts that have enabled status scientometrics recognized as a separate discipline. Author of the first citation index of papers published in scientific journals Eugene Garfield, who was with de Sollu Price's often associated with the founders scientometrics. Garfield proposed the first citation index of Sciences in 1953 on the model of Shepard quotes [15], citation index of legal documentation which is the first version of Frank Shepard started making more in 1873 [1]. 


\section{ORCID number}

Growing number of authors and lot of authors with same name and surname led to the the introduction of the necessary identification agent. Academics, researchers and contributors can register for a unique ID with ORCID (Figure 1) (the Open Researcher and Contributors ID repository) - these identifiers can be used by editors, funding agencies, publishers and institutions to reliably identify individuals in the same way that ISBNs and DOIs identify books and articles [18-22] (Figure 3).

\section{Bosnia and Herzegovina Biomedical Publishing}

In 2015 in Bosnia and Herzegovina (B\&H) about twenty five journals are issued in the field of biomedical and life sciences in general - Journals that are indexed in Medline/PubMed are Medical Archives (established in 1947), Materia Socio-Medica (established in 1978), Acta Informatica Medica (established in 1993), Acta Medica Academica (established in 2008), Bosnian Journal of Basic Medical Sciences (BJBMS) (established in 2004) and Medicinski Glasnik (established in 2007) [19,20]. Ana Wil Harzing, from Melbourne, Australia, in 2006 launched a free of charge available software package called "Publish or Perish", which is used for the derivation of various citation analyses, including impact factor [16-20]. We analyzed the most profilic authors of $\mathrm{B} \& \mathrm{H}$ by mentioned software (the highest $\mathrm{H}$-index has Izet Masic $\mathrm{MD}, \mathrm{PhD}$ ) (Table 1). The most relevant indicator of the work of one author is however the number of articles available in the PubMed database. Situation in B\&H is analyzed and presented in Tables 2 and 3 , Figure 4 .

\section{Conclusion}

The study of quantitative aspects of the creation, transfer and use of scientific and other key information, is one of the most important areas within information science. According to $\mathrm{H}$. White and $\mathrm{K}$. McCain, by the end of the eighties of the last century almost half of the total published papers of information sciences was related to this issue, and about the same trend is maintained thereafter. Direct reason for these studies, whose origins arise in the first half of the twentieth century, was more pronounced awareness of the need to establish a system of scientific and technological information, and the results have contributed to establishing them more significantly.

The literature identifies as bibliometric, scientometric or informetrics research, depending on the title you are a discipline that

\section{DISTINGUISH YOURSELF IN THREE EASY STEPS}

ORCID provides a persistent digital identifier that distinguishes you from every other researcher and, through integration in key research workflows such as manuscript and grant submission, supports automated linkages between you and your professional activities ensuring that your work is recognized. Find out more.

REGISTER Get your unique ORCID identifier Register now! Registration takes 30 seconds.

ADD YOUR Enhance your ORCID record with your $\begin{array}{ll}\text { INFO } & \text { professional information and link to your other } \\ \text { identifiers (such as Scopus or ResearcherID or }\end{array}$ Linkedln).

USE YOUR Include your ORCID identifier on your Webpage, ORCID ID when you submit publications, apply for grants, and in any research workflow to ensure you get credit
for your work.

Figure 3: ORCID web presentation (orcid.org).

\begin{tabular}{|l|c|}
\hline Author & H-index \\
\hline Izet Masic & 14 \\
\hline Semir Vranic & 13 \\
\hline Enver Zerem & 13 \\
\hline Ljerka Ostojic & 12 \\
\hline Osman Sinanovic & 11 \\
\hline Azra Alajbegovic & 9 \\
\hline Mirsada Hukic & 9 \\
\hline Abdulah Kucukalic & 9 \\
\hline Husref Tahirovic & 9 \\
\hline Mirza Dilic & 8 \\
\hline Farid Ljuca & 8 \\
\hline Aida Kulo & 8 \\
\hline Halima Resic & 7 \\
\hline Adlija Causevic & 7 \\
\hline Semir Beslija & 6 \\
\hline Almira Hadzovic Dzuvo & 6 \\
\hline Rusmir Mesihovic & 6 \\
\hline Nermin Salkic & 6 \\
\hline Sedin Kobaslija & 6 \\
\hline Haris Pandza & 6 \\
\hline
\end{tabular}

Table 1: Most profilic authors in B and $\mathrm{H}$ (top 20) analyzed by Publish or Perish software (based on Google Scholar database) - ordered by $\mathrm{H}$ index (20).

\begin{tabular}{|l|c|}
\hline Author & PubMed \\
\hline Izet Masic & 303 \\
\hline Osman Sinanovic & 100 \\
\hline Enver Zerem & 97 \\
\hline Husref Tahirovic & 70 \\
\hline Abdulah Kucukalic & 57 \\
\hline Halima Resic & 54 \\
\hline Azra Alajbegovic & 53 \\
\hline Semir Vranic & 52 \\
\hline Mirsada Hukic & 52 \\
\hline Farid Ljuca & 49 \\
\hline Jasenko Karamehic & 43 \\
\hline Vjekoslav Gerc & 39 \\
\hline Ljerka Ostojic & 38 \\
\hline Dragana Niksic & 38 \\
\hline Jasminko Huskic & 38 \\
\hline Rusmir Mesihovic & 37 \\
\hline Nermin Salkic & 37 \\
\hline Mirza Dilic & 37 \\
\hline Slobodan Loga & 36 \\
\hline Marko Buksa & 34 \\
\hline
\end{tabular}

Table 2: Most profilic authors in B and $\mathrm{H}$ (top 20) ordered by number of articles (based on PubMed).

deals with this issue bibliometrics, scientometrics or informetrics and there really is a problem. In fact, despite occasional rhetoric about the differences between bibliometrics, scientometrics and informetrics minimal and negligible in terms of differentiation, there is still a division into three related but distinct disciplines. The consequences are visible on the conceptual, and especially the terminology level, and to the proliferation of calls with no clear meaning, which is essentially obstructive process.

Although the importance of the systematic editing of the entire field of information. Science that deals with quantitative research warned badges at the end of the seventies of the last century, proposing the establishment of a single discipline, the debate on this issue are usually pushed aside. And despite recently repeatedly emphasized the 
Page 10 of 11

\begin{tabular}{|c|c|c|c|c|c|c|c|c|c|c|c|}
\hline & Documents & $\begin{array}{c}\text { Citable } \\
\text { Documents }\end{array}$ & Cites & Self Cites & $\begin{array}{l}\text { Cites per } \\
\text { Doc. }\end{array}$ & $\begin{array}{l}\text { Self Cites per } \\
\text { Doc. }\end{array}$ & $\begin{array}{l}\text { Cited } \\
\text { Docs. }\end{array}$ & $\begin{array}{l}\text { Uncited } \\
\text { Docs. }\end{array}$ & $\begin{array}{l}\text { \% International } \\
\text { Collaboration }\end{array}$ & $\%$ Region & \% World \\
\hline 1996 & 14 & 11 & 173 & 5 & 12.34 & 0.36 & 13 & 1 & 44.29 & 7 & 0 \\
\hline 1997 & 12 & 12 & 215 & 17 & 17.92 & 1.42 & 11 & 1 & 81.33 & 0.13 & 0 \\
\hline 1998 & 12 & 12 & 122 & 13 & 10.17 & 1.03 & 9 & 3 & 50.00 & 0.13 & 0 \\
\hline 1999 & 12 & 11 & 105 & 10 & 8.75 & 0.83 & 9 & 3 & 25.00 & 0.13 & 0 \\
\hline 2000 & 7 & 5 & 141 & 19 & 20.14 & 2.71 & 6 & 1 & 5704 & 0.07 & 0 \\
\hline 2001 & 20 & 18 & 175 & 19 & 8.75 & 0.95 & 16 & 4 & 20.00 & 0.18 & 0 \\
\hline 2002 & 22 & 16 & 218 & 7 & 9.91 & 0.32 & 13 & 9 & 45.45 & 0.19 & 0 \\
\hline 2033 & 48 & 43 & 243 & 48 & 5.06 & 1.00 & 33 & 15 & 39.58 & 0.35 & 0.01 \\
\hline 2004 & 51 & 51 & 745 & 44 & 14.61 & 0.86 & 37 & 14 & 5490 & 0.34 & 0.01 \\
\hline 2035 & 54 & 53 & 524 & 94 & 9.70 & 1.74 & 39 & 15 & 62.96 & 0.32 & 0.01 \\
\hline 2006 & 85 & 82 & 485 & 73 & 5.71 & 0.86 & 58 & 27 & 54.12 & 0.47 & 0.01 \\
\hline 2007 & 101 & 97 & 979 & 129 & 949 & 1.28 & 72 & 29 & 58.42 & 0.55 & 0.02 \\
\hline 2008 & 213 & 211 & 1.077 & 118 & 5.06 & 0.55 & 141 & 72 & 31.46 & 1.04 & 0.03 \\
\hline 2009 & 224 & 219 & 1.004 & 105 & 4.48 & 0.47 & 145 & 79 & 30.80 & 1.02 & 0.03 \\
\hline 2010 & 274 & 268 & 1.538 & 137 & 5.61 & 0.5 & 163 & 111 & 33.94 & 107 & 0.04 \\
\hline 2011 & 305 & 289 & 986 & 73 & 3.23 & 0.24 & 166 & 139 & 42.30 & 1.18 & 0.04 \\
\hline 2012 & 274 & 252 & 594 & 71 & 2.17 & 0.26 & 134 & 140 & 44.16 & 1.02 & 0.04 \\
\hline 2013 & 202 & 188 & 181 & 27 & 1.89 & 0.13 & 87 & 115 & 53.47 & 0.73 & 0.03 \\
\hline 2014 & 221 & 200 & 58 & 11 & 0.26 & 0.05 & 37 & 184 & 50.23 & 0.83 & 0.03 \\
\hline
\end{tabular}

Table 3: B and $\mathrm{H}$ medical publishing according to scimagojr.com (period 1996-2014).

\begin{tabular}{|c|c|c|c|c|c|c|}
\hline Country & Documents & $\begin{array}{l}\text { Citable } \\
\text { documents }\end{array}$ & Citations & Self-Citations & $\begin{array}{l}\text { Citations per } \\
\text { Document }\end{array}$ & $H$ index \\
\hline $1=$ Poland & 104.962 & 99.984 & 954.883 & 167.713 & 10,39 & 263 \\
\hline 2 L C Zech Republic & 51.689 & 49.105 & 497.617 & 78.567 & 10,53 & 213 \\
\hline 3 = Russian Federation & 43.190 & 42.227 & 426.571 & 71.190 & 11,22 & 189 \\
\hline $4=$ Hungary & 32.294 & 30.366 & 483.596 & 57.052 & 16,40 & 206 \\
\hline 5 동aia & 21.599 & 20.296 & 142.089 & 25.024 & 7,39 & 112 \\
\hline 6 [| Romania & 14.539 & 13.738 & 108.641 & 10.884 & 10,28 & 111 \\
\hline 7 Slovakia & 13.454 & 12.715 & 128.331 & 16.371 & 10,34 & 123 \\
\hline 8 a Slovenia & 11.987 & 11.330 & 143.430 & 18.756 & 14,31 & 119 \\
\hline 9 - Bulgaria & 10.810 & 10.368 & 92.733 & 8.479 & 8,76 & 102 \\
\hline 10 a Serbia & 10.186 & 9.407 & 50.339 & 6.529 & 17,94 & 75 \\
\hline 11 日kraine & 5.663 & 5.557 & 67.040 & 9.021 & 13,12 & 93 \\
\hline $12=$ Estonia & 4.275 & 4.123 & 81.593 & 7.677 & 21,98 & 106 \\
\hline 13 - Lithuania & 4.090 & 3.937 & 58.513 & 4.439 & 20,32 & 90 \\
\hline 14 \ Bosnia and Herzegovina & 2.151 & 2.038 & 9.763 & 1.020 & 8,18 & 39 \\
\hline 15 E Belarus & 2.110 & 2.066 & 26.296 & 2.881 & 13,27 & 71 \\
\hline 16 路 Macedonia & 1.692 & 1.571 & 12.935 & 961 & 9,74 & 49 \\
\hline 17 回 Azerbaijan & 1.595 & 1.569 & 3.602 & 101 & 5,53 & 25 \\
\hline 18 E Latvia & 1.488 & 1.439 & 29.160 & 1.507 & 25,30 & 72 \\
\hline $19+$ Georgia & 1.124 & 1.044 & 12.402 & 620 & 13,17 & 50 \\
\hline $20 \Xi$ Armenia & 896 & 854 & 6.262 & 635 & 9,77 & 36 \\
\hline 21 圆 Albania & 583 & 548 & 4.730 & 282 & 11,77 & 33 \\
\hline 22 [ण] Moldova & 340 & 324 & 2.559 & 194 & 10,80 & 27 \\
\hline 23 [a Montenegro & 278 & 272 & 851 & 48 & 4,43 & 13 \\
\hline
\end{tabular}

Figure 4: $\mathrm{B}$ and $\mathrm{H}$ position in Eastern Europe region according to scimagojr. com (for 2014) - ordered by number of documents [22].

view that the area of quantitative research in a crisis, as the cause of the crisis is rarely stated unnecessary fragmentation of areas, followed by the unmatched terminology and theory, which in its major part gives the impression of an ad hoc structure.

Starting from a) the existing situation in the field of quantitative research) changes resulting from the strong development of information and communication technologies, try to point out the following: first, that the existing disciplinary division no purpose because it is not brought to the Real area, on the contrary cause his crudity; second, that the creation of a difference as a criterion for division, used and still use evidence of questionable validity; third, that the establishment of a single discipline is a necessary precondition for further development, especially after the advent of changes occurred with webometrics encouraged the establishment of global information net articles and systems such as the Internet and Web.

\section{References}

1. Masic I, Kujundzic E (2013) Science Editing in Biomedicine and Humanities. Avicena Sarajevo.

2. Masic I (2011) How to search, write, prepare and publish the scientific papers in the biomedical journals. Acta Inform Med 19: 68-79.

3. Masic I, Sabzghabaee AM (2014) How clinicians can validate scientific contents? J Res Med Sci 19: 583-585.

4. Amanda (2012) Cracking open the scientific process. Science and Engineering Libraries Blog, Columbia University, USA.

5. (2016) ResearchGate sheet. University of Leeds, Leeds, UK.

6. Hardy Q (2012) Failure is the next opportunity.

7. Scot M (2014) Europeans look beyond their borders. BITS.

8. Hamm S (2009) ResearchGate and its Savvy use of the Web. Bloomberg Business.

9. Crawford M (2011) Biologists using social-networking sites to boost collaboration. BioScience 61: 736-736.

10. Labbe C, Labbe D (2013) Duplicate and fake publications in the scientific literature: how many Scgen papers in computer sciences? Scientometrics 94 : 379-96.

11. Hirsch JE (2005) An index to quantify an individual's scientific research output. Proc Natl Acad Sci USA. 102: 16569-16572.

12. Masic I (2013) Medical publication and scientometrics. J Res Med Sci 8: 516-521.

13. Silobrcic $\vee(2015)$ How to increase the impact factor of a scientific journal? Donald School, J Ultrasound Obstet Gynecol 9: 357-360.

14. Garfield E (1999) Journal impact factor: a brief review. CMAJ 161: 979-980.

15. Masic I (2016) Scientometric analysis: a technical need for medical science researchers either as authors or as peer reviewers. J Res Pharm Pract 5: 1-6.

16. Masic I, Begic E (2015) Meta-analysis as statistical and analytical method of Journal's Content Scientific Evaluation. Acta Inform Med 23: 4-11.

17. Masic I, Begic E, Zunic L (2016) Scientometric analysis of scientific validity of medical archives regarding other medical journals in Bosnia and Herzegovina 70: $18-26$. 
Citation: Masic I (2016) Index Factors for Assessing the Scientific Journal Validity, It's Articles and Their Authors. J Forensic Anthropol 1: 103.

Page 11 of 11

18. Masic I, Begic E, Zunic L (2016) Scientometric analysis of the journals of the academy of medical sciences in Bosnia and Herzegovina. Acta Inform Med 24: $4-11$

19. Eghbal MJ, Davari Ardakani N, Asgary S (2012) A Scientometric Study of PubMed-Indexed endodontic articles: A Comparison between Iran and Other regional countries. Iranian Endodontic Journal 7: 56-9.

20. SCImago Journal \& Country Rank. SJR.

21. Masic I (2016) H-index and how to improve it.
22. Masic I (2013) The importance of proper citation of references in biomedical articles. Acta Inform Med 21: 148-155.

23. Masic , Hodzic A, Mulic S (2014) Ethics in medical research and publication. Int J Prev Med 5: 1073-1082.

24. Masic I (2014) Plagiarism in scientific research and publications and how to prevent it. Mater Sociomed 26: 141-146.

25. Masic I (2012) Plagiarsim in scientific publishing. Acta Inform Med 20: 4-10. 